\title{
Interdisciplinary integration as a basis for forming an environment-oriented component of competencies
}

\author{
Olga Vasina $^{1,{ }^{*}}$, Olga Ponomariova $^{2}$, Tatiana Kotelnikova ${ }^{3}$ \\ ${ }^{1}$ Penza State University, Department of General Biology and Biochemistry, 440026, 40 Krasnaya \\ Street, Penza, Russia \\ ${ }^{2}$ A.V. Khrulev Penza Branch of the Military Academy of Logistics, Department of Humanities and \\ Socioeconomic Disciplines, 440005, Penza, Russia \\ ${ }^{3}$ Penza Social Pedagogical College, Department of Primary School Education, 440052, 3 Gogol \\ Street, Penza, Russia
}

\begin{abstract}
Most disciplines of the compulsory part of the curriculum and its part defined by education stakeholders in line with the corresponding study field have a significant resource for forming an environment-oriented component of competencies in students. The authors aim at identifying and showing the possibilities of interdisciplinary integration in the formation of the environment-oriented component of universal and professional competencies in the process of fulfilling the requirements of the Federal State Educational Standards. The article illustrates the practice of implementing interdisciplinary integration in higher education when forming the environment-oriented component of competencies by means of experimental work within the educational process at Penza State University and A.V. Khrulev Penza Branch of the Military Academy of Logistics. It is shown that the interdisciplinary integration implies not complementing the disciplines with additional ecological content, but creating a new system with emergent properties that are of interest of both environmental and field-specific education.
\end{abstract}

\section{Introduction}

The practical implementation of interdisciplinary integration has been actively explored in recent years. This is reflected in the publications of V.N. Maximova, V.N. Fedorova, V.M. Monakhov, E.N. Knyazeva, P.T. Kulagin, N.A. Loshkareva, V.E. Medvedev, S.I. Popova, O.D. Shabalin and others $[7 ; 8 ; 9 ; 16 ; 17]$. Interdisciplinarity in higher education is currently viewed as a synthesis of professional and social ideas, as one of the leading didactic principles and methodological approaches and as a result of processes of differentiating and integrating acquired scientific and academic knowledge. The Federal State Educational Standards include requirements for the structure, workload, implementation and learning outcomes following the successful completion of the basic professional educational programmes, but do not determine the educational content. The

\footnotetext{
* Corresponding author: onvasina@yandex.ru
} 
standards provide leeway in designing educational programmes and enable their environmentalisation based on interdisciplinarity and unity of compulsory (formal) education, further (non-formal) education and awareness-raising (informal education). The integration of the environment-oriented component into most disciplines of the compulsory part of the curriculum and its part defined by education stakeholders in line with the corresponding study field has a great capacity for promoting emotional and values-based attitude to nature $[10 ; 11 ; 13]$. Its aim is to identify and show the possibilities of interdisciplinary integration when forming the environment-oriented component of universal and professional competencies in compliance with the requirements of the Federal State Educational Standards. The scope of research is the educational process in higher education. The focus of research is the interdisciplinary environment-oriented integration in higher education.

\section{Theory and research methodology}

The theoretical framework for research is the publications of V.V. Nikolina, G.E. Zalessky, I.Ya. Lerner, V.V. Kraevsky, O.N. Ponomariova, A.N. Zakhlebny, E.N. Dzyatkovskaya, and D.S. Ermakov $[2 ; 4 ; 5 ; 6 ; 12 ; 14 ; 16]$. The competence-based, culture-based and interdisciplinary approaches $[5 ; 13 ; 14]$ serve as a methodological basis for research.

The competency-based approach lies at the core of fulfilling the requirements of the Federal State Educational Standards directed at training of higher education graduates with professional competencies essential for society in general and an individual employer in particular. At the same time, there is a shift in the aim of education from predominantly theoretical training of students to practice-oriented training of a qualified person capable of responding to various challenges using his / her knowledge, skills and abilities (V.A. Bolotova, V.V. Davydov, P.Y. Galperin, I.A. Zimnyaya, V.I. Gorbachev, E.F. Zeer, E.Ya. Kogan, O.E. Lebedev, E.A. Lenskoy, A.A. Pinsky, V.V. Serikov, N.V. Troshin, I.D. Frumina, A.V. Khutorskoy, V.D. Shadrikov and others) [3; 5; 15].

The culture-based approach is the key to selecting the educational content with regard to acquiring and fostering culture in a purposeful and consistent way, providing conditions not only for the acquaintance, but also for the immersion in culture and assimilation of cultural values. According to scientists, the educational content goes beyond the content of sciences and it is not limited to their foundations (the academic discipline and the foundations of sciences are considered as a part and as a whole). Hence, the educational content is defined as a pedagogically adapted social experience represented by four components:

1. Knowledge about nature, society, technology, human, and methods of activity;

2. Experience in employing the known methods of activity, which are embodied along with knowledge in skills and abilities of a person;

3. Experience of creative activity, which is represented in special intellectual procedures that cannot be described in the form of algorithms;

4. Experience of emotional and value-based attitude to reality, which is realised in a set of values that play a motivational role in behaviour and determine the choice of methods for managing life in general and specific activity in particular (V.V. Kraevsky, I.Ya. Lerner, G.V. Mukhametzyanova, A.M. Novikov, I.M. Osmolovskaya, O.N. Ponomariova, M.N. Skatkin, A.V. Khutorskoy and others) $[1 ; 3 ; 4 ; 12 ; 15]$.

In addition to the fact that the experience of emotional and value-based attitude is the main component of the educational content (according to I.Ya. Lerner), it determines the relationship between education stakeholders and presupposes the expression of emotions, which include love for parents and relatives, respect for homeland, deep knowledge of ancestry, native language, culture, and history of the people, caring for the young ones, empathy, and loyalty to customs. This is the basis of education [14]. 
The interdisciplinary approach is the framework for using interdisciplinary connections to synthesise environment-oriented materials in various disciplines / modules, while all structural elements of social experience are detailed in the content of the discipline / module in line with the focus of the academic discipline and its specific features. Under professional training (regardless of its area), the environment-oriented materials (as a component of social experience) are obtained, assimilated and transmitted in the process of interdisciplinary integration (within natural sciences and humanities), which contributes to the formation of basic knowledge and skills in the field of ecology and nature conservation and, mainly, to the achievement of personal outcomes in the field of culture. At that, the environment-oriented component is integrated with the economic, political, legal, and cultural ones (V.N. Maksimova, V.N. Fedorova, V.M. Monakhov, E.N. Knyazeva, P.T. Kulagin, N.A. Loshkareva, V.E. Medvedev, S.I. Popova, O.D. Shabalina) [7; 8; 9; 16; 17].

An important element of the environment-oriented component of competencies is a pattern of emotional and values-based attitude to nature, which can facilitate changing the attitude towards other environmental objects and various activities. Favourable emotional and values-based attitude to nature adopted by a person is actively manifested in emotional and values-based attitude towards personal health, other people, labour, profession, homeland, world as a whole $[15 ; 19 ; 20]$. However, higher education ignores the materials accumulated by pedagogical science on the formation of positive emotional and valuesbased attitude (methodology of geography, methodology of ecology, etc.). Neither didactic tasks for its generation in the youth are clearly formulated, nor effective psychological and pedagogical ways of their solution are defined. In addition, the environment-oriented potential of various academic disciplines is not taken into consideration $[14 ; 15]$.

Ecology as a science associated with almost any study field and accompanied by the simultaneous development of new integrative branches (e.g. urban ecology, ecological linguistics, military ecology, radioecology, bioindication, geoinformatics, psychological ecology, space ecology) has a significant resource for forming the environment-oriented component of competencies. Environmental problems are also multidisciplinary, which can be studied within any discipline. In fact, these problems unite different study fields in the search for solutions. When selecting the materials and their content, it is important to recognise the invariable (general theoretical understanding) and variable (academic material, discipline / module) levels of interdisciplinary integration. The invariable level ensures implementing the educational content on a regulatory and legal basis that is characterised by fundamental and integrative focus on professional activity. The variable level contributes to implementing the educational content within the disciplines / modules of the compulsory part of the curriculum and its part defined by education stakeholders (taking into account academic and on-the-job training targeted at professional development) and within awareness-raising.

An important condition for environment-oriented integration is complementing the content of the disciplines in the compulsory part and the part defined by education stakeholders with adapted social experience combining experience in environment-oriented cognitive, physical and creative activity and emotional and values-based attitude to nature $[12 ; 14 ; 15 ; 18]$. The authors consider designing the content of environmental education as a system of assimilating adapted social experience uniting gnoseological, activity-based, creative, axiological (value-based) elements, the ecological focus of which contributes to forming and developing the environment-oriented component of competencies.

The gnoseological (knowledge-based) element combines environmental knowledge gained by mankind about the biosphere, noosphere, and human as their part, about the unity of their existence and development, about the rules and norms of their interaction, about the contradictions, emerging environmental problems, possible ways and means of their 
solution. Environmental knowledge determines positioning of a person in the reality and in the value paradigm. The greater the scope and consistency of acquired knowledge are, the broader the outlook of the student is, the more objects can enter the paradigm of his / her personal values. The assimilation of this element of the content determines the capability to:

- define basic environmental concepts;

- establish and explain cause-and-effect relationships in nature;

- $\quad$ predict effects of environmental phenomena, view and analyse probabilistic processes;

- apply acquired knowledge in new contexts when solving new problems.

The activity-based element covers environment-oriented skills and abilities acquired by a person to conserve nature, undertake rational environment-oriented activity, build daily life, provide environmental education, etc. The abilities determined by the acquired knowledge and skills enable students to act according to the model:

- independently tackling environment-oriented tasks / problems, exploring them (including acquiring necessary knowledge);

- correctly setting aims in accordance with the objective conditions, which may influence their feasibility and attainability;

- addressing environment-oriented tasks / problems in line with the aim and available resources, adopting specific means and methods, improving and working out them in progress, fulfilling the aim.

The creative element presupposes applying the environmental approach to handle current problems in professional activity and to solve environmental problems in current work. It facilitates the development of the ability to effectively handle environmentoriented tasks / problems:

- independently transferring knowledge and skills to a new environment-oriented task / problem;

- identifying a new challenge in a familiar environment-oriented task / problem;

- defining a new function of an environment-oriented task / problem and recognising its structure;

- independently combining well-known methods of environment-oriented activity into a new one;

- presenting an alternative and diversified view of possible solutions to an environmentoriented task / problem in case of conflicting evidence;

- $\quad$ building a fundamentally new way of solving environment-oriented tasks / problems in contrast to other known ways (this new way should not be a combination of the known ones).

The axiological (value-based) element implies discovering the morality of relationship between mankind and nature, which ensures the assimilation of universal values. It allows planning how students master such activities (environment-oriented component of competencies) as search, retrieval, interpretation, evaluation and analysis of new environment-oriented information. Through the assimilation of this component students learn how to frame environmental concepts, to observe and examine causes and effects in nature, to measure positive and negative impact of environmental phenomena, to consider and evaluate natural processes, to use gained knowledge and skills in new contexts.

In turn, the integration of the environment-oriented component and the economic, political, legal, and cultural ones is ensured through aligning the content and information among academic disciplines, applying available environmental knowledge (factual, theoretical, practical) in new situations and testing them. Under interdisciplinary environment-oriented integration, it is not the additional ecological content, which is introduced into the discipline, but a new system with emergent properties that are of 
interests of both environmental and field-specific education, which is created. This approach enables students to understand the essence of human attitude to the social and natural environment and clears the way for fostering an environment-centred type of ecological awareness and for shaping favourable emotional and values-based attitude [3; 4; $13 ; 15]$. The capacity and willingness to set and accomplish the worldview, methodology and value objectives of self-identification, self-determination, self-actualisation and personal development can be realised at the same time [15].

\section{Results and findings}

The major aim of modern higher education is to teach a person to address problems in various areas of life, including the professional one. In this respect, a graduate is regarded as having professional competencies, the structure of which includes:

1. Knowledge as a set of facts required to perform professional duties (knowledge represents the intellectual context, in which a person exists);

2. Skills and abilities, which presupposes adopting and employing means and methods to fulfil specific tasks (polished skills and abilities are reflected in different ways - from physical powers and dexterity to specialised training);

3. Capabilities being the individual psychological characteristics of a person, which determine the "successful" or "unsuccessful" performance of this or that activity (at that capabilities are not reduced to the knowledge-skills-abilities set of a person);

4. Stereotyped behaviours, which are considered as the visible forms of actions taken to complete a task; behaviour includes inherited and acquired reactions of a person to situations and situational stimuli; behaviour displays values, moralities, beliefs and reactions to the environment (when a person demonstrates self-confidence, builds a team, shows action bias, and his / her behaviour meets the requirements of the organisation, the key aspect is observing this behaviour);

5. Efforts (volitional) consist in applying mental and physical resources in a conscious way in certain contexts (the ability to force oneself is the basis to achieve results and produce outcomes) [3; 15].

Regardless of the academic discipline / module and throughout the entire period of study, the universal competencies are formed by means of systematic integration into the educational process through the content, technology and environment. However, the list of competencies does not include the concept of environmental competency. Meanwhile, this is an essential aspect of training, including values and ideas of environment-oriented activity, basic environmental knowledge, as well as experience in solving socially significant environmental problems [3]. As the environmental competency is not distinguished, the authors believe that it possible to single out the environment-oriented component of competencies, which is an important element of professional competence required for a higher education graduate to develop and succeed in the labour market.

The experimental work results in identifying the leading environment-oriented components of universal competencies:

- broadening social experience of interaction between nature and society, advancing ecological thinking and ecological consciousness, adopting emotional and values-based attitude;

- extending practical and theoretical environmental knowledge and skills, including for the development and implementation of environment-oriented projects;

- examining and explaining cause-and-effect relationships, exchanging best practices, distributing responsibilities under environment-oriented team activity;

- establishing communication and intercultural interaction to solve problems / tasks and to undertake environment-oriented activity; 
- evaluating and analysing the impact of environmental factors on human health, human development and life safety.

The identified pedagogical conditions have been implemented in practice since 2016 . This process is currently ongoing, when delivering the educational programmes within the study field 44.00.00 Education Sciences (at V.G. Belinsky Institute of Teacher Education) and within the study fields 33.05.01 Pharmacy, 31.05.01 General Medicine, 31.05.02 Paediatrics, 31.05.03 Dentistry (at Medical Institute) at Penza State University, as well as when providing the academic disciplines at A.V. Khrulev Penza Branch of the Military Academy of Logistics.

The results indicate a significant educational potential for forming the environmentoriented component of competencies under the academic disciplines: Life safety, Biology and ecology, Military history, Biological underpinnings of living systems, Military topography, Culture studies, Biology, Age anatomy, physiology and hygiene, Chemical, biological, radiological and nuclear defence, Ecology, Geography, Fundamentals of medicine, Chemistry, Ecology and life safety.

The interdisciplinary integration is possible under the following academic conditions:

- including adapted social experience in the content of higher and further education, which combines the experience in environment-oriented cognitive activity, in environment-oriented work methods, in environment-oriented creative activity, as well as in emotional and values-based attitude to nature, society, homeland, health, and profession;

- adding the environment-oriented component to the disciplines in the compulsory part and the part defined by education stakeholders in line with the corresponding study field in order to unite the interrelated gnoseological, activity-based, creative, axiological (value-based) elements reflecting the social environment-oriented experience in its structural completeness;

- $\quad$ saturating the discipline content with fragments of classic fiction and popular science books and information about life experience of various generations stored in proverbs, sayings and other cultural elements;

- tackling the environment-oriented tasks / problems that are significant for the student, under which he or she can adopt practical measures that have real benefits;

- raising the environment-oriented interdisciplinary issues;

- applying the active and interactive methods and techniques with the view to personal experience of students, i.e. outcomes of formal, non-formal and informal environmental teaching and learning and environmental knowledge integrating;

- immersing in the social and cultural ecology-oriented environment of the educational institution in line with the natural and cultural heritage and feasible personal contribution to the social sustainability.

To provide didactic assistance to teaching staff in designing and implementing environmental training and forming the environment-oriented component of universal and professional competencies, a didactic set "Ecology" in six volumes was developed and introduced into the educational process $[15 ; 19 ; 20]$ :

1. Ecology. Study Guide provides didactic support for teaching staff. Its materials are used to manage and organise educational activities of an academic type for the assimilation of knowledge by students. The four topic sections of the guide (namely, Fundamentals of ecology, Fundamentals of social ecology, Fundamentals of environmental management, and Global problems of our time) combine the basic ecological concepts and patterns and reveal the features of modern environmental problems.

2. Ecology. Drill Book offers teaching support for the educational process. It presents environment-oriented tasks that stimulate cognitive interest and mental activity of 
students. In addition, the book contains case tasks for roundtable discussions, SWOT analysis, and brainstorming and test tasks for formative and summative assessment to gain feedback, reflect and redirect students' efforts.

3. Ecology. Reading Book as information educational support of the educational process includes environment-oriented texts, which are represented by ecology-filled fragments of art, popular science, social and political publications by Russian and foreign authors. These texts are complemented by the first developed set of tasks and exercises.

4. Ecology. Teacher's Book provides management support for the environment-oriented educational process and gives methodological recommendations for planning and organising students activity based on feedback. It characterises the features of the environment-oriented educational process and distinguishes the techniques, means and methods of using environment-oriented materials. It also presents a variety of tasks with keys for formative and summative assessment.

5. Ecology. Workbook for Practical and Laboratory Classes gives an insight into arranging practical and laboratory activity. It compensates for the lack of modern educational materials necessary for conducting practical and laboratory classes with the environment-oriented content for students within the non-core study fields in higher and further education.

6. Ecology. Workbook includes materials of lectures, practical and laboratory classes on the fundamentals of ecology. Moreover, it contains tasks for curricular and extracurricular activity of students during unsupervised learning.

\section{Conclusion}

The practice of establishing and fostering interdisciplinary environment-oriented links at Penza State University (V.G. Belinsky Institute of Teacher Education and Medical Institute), as well as at A.V. Khrulev Penza Branch of the Military Academy of Logistics, shows that the interdisciplinary integration aimed at improving environmental knowledge and skills, broadening experience in ecology and nature conservation, promoting emotional and values-based attitude to nature contributes to the formation of the environment-oriented component of competencies in the process of professional training. The didactic set "Ecology" was released to provide didactic assistance to teaching staff in forming the environment-oriented component of competencies in students. This set is represented by a system of structurally integral components: didactic support, teaching support (collection of tasks), information support (environment-oriented texts), and management support (recommendations for managing teaching and learning with regard to feedback).

\section{References}

1. O.N. Vasina, Bulletin of Higher Education Institutions, 4 (2009)

2. O.N. Vasina, Forming emotional and values-based attitude to nature among secondary school children through folk ecology traditions: Thesis (Penza, 2004)

3. O.N. Vasina, Bulletin of the North-Caucasus Federal University, 5 (2019)

4. E.N. Dzyatkovskaya, Modern Teacher Training, 6 (2020)

5. A.N. Zakhlebny, E.N. Dzyatkovskaya, I.V. Wagner, A.Yu. Liberov, Environmental Education: before School, at School, after School, 2 (2012)

6. A.N. Zakhlebny, School and Nature Conservation Challenges (Moscow, 1981)

7. O.V. Zorkina, O.N. Vasina, Humanities and Education, 10, 2 (2019)

8. V.G. Ivanov, T.A. Ivanova, Vocational Secondary Education, 12 (2000) 
9. E.N. Knyazeva, Philosophy of science. Interdisciplinary research strategies: Textbook (Moscow, 2019)

10. Authoring team, Best practices of environmental education for sustainable development (St. Petersburg, 2017)

11. I.V. Lysak, Modern Challenges in Science and Education, 5 (2016)

12. V.V. Nikolina, Human and Education, 1 (2020)

13. V.I. Panov, Psychological Diagnosis, 1 (2012)

14. O.N. Ponomariova, Methodical system of teaching ecology in secondary school: Thesis (Penza, 2000)

15. O.N. Ponomariova, O.N. Vasina, M.V. Smyshlyaev, Bulletin of Higher Education Institutions, 3 (2017)

16. V.A. Romanov, Alphabetical list of topics for doctoral theses in pedagogy and psychology in 1937-2017 (Tula, 2018)

17. O.D. Fedorova, Logos, 1 (2014)

18. I.A. Fedoseeva, Integration of University Science into Social Institutions System: Russian and American Practices (2018)

19. O.N. Ponomariova, O.N. Vasina, International Journal of Environmental and Science Education, 11, 15 (2016)

20. O.N. Vasina, O.N. Ponomariova, European Proceedings of Social and Behavioural Sciences, 90 (2018) 